\title{
Heroin Addiction: Anticipating the Reward of Heroin or the Agony of Withdrawal?
}

\author{
Magalie Lenoir and Ronald Keiflin \\ Laboratoire de Neuropsychobiologie, Université Victor Segalen Bordeaux 2, Centre National de la Recherche Scientifique, Unité Mixte de Recherche 5541, \\ 33076 Bordeaux, France
}

Review of Kenny et al. (http://www.jneurosci.org/cgi/content/full/26/22/5894)

What drives compulsive drug use and relapse in addicts is still controversial (Robinson and Berridge, 2003). According to positive-reinforcement theories of drug addiction, the compulsion to take drugs results from an increase in the rewarding or incentive effects of drugs of abuse with chronic exposure, attributable to sensitization and/or associative conditioning. In contrast, according to negativereinforcement theories, addicts are compelled to take drugs to avoid the unconditioned and/or conditioned negative affective consequences of drug withdrawal. The recent article by Kenny et al. (2006) in the Journal of Neuroscience provides strong support for the latter explanation by showing that withdrawal-induced decrease in brain reward drives compulsive heroin use.

Brain reward was probed using intracerebral self-stimulation in nondependent rats with stable/moderate heroin use (access to heroin limited to $1 \mathrm{~h} / \mathrm{d}$ ) and in dependent rats with escalating/compulsive heroin use (unlimited access to heroin). A stimulating electrode was placed in the lateral hypothalamus, a region at the heart of the brain reward system. After recovery, animals were allowed to selfstimulate this region by turning a wheel.

Received July 1, 2006; revised July 25, 2006; accepted July 25, 2006. Correspondence should be addressed to Ronald Keiflin, Laboratoire de Neuropsychobiologie, Université Victor Segalen Bordeaux 2, Centre National de la Recherche Scientifique, Unité Mixte de Recherche 5541, 146 rue Léo-Saignat, 33076 Bordeaux, France. E-mail: ronald.keiflin@etud.u-bordeaux2.fr.

DOI:10.1523/JNEUROSCI.2808-06.2006

Copyright $\odot 2006$ Society for Neuroscience $\quad$ 0270-6474/06/269080-02\$15.00/0
After stabilization of the self-stimulation behavior, the intensity of the electrical stimulation was varied using the method of limits. This method allows the detection of the minimum current intensity that maintains self-stimulation. This reward threshold is an operational measure of the activity of the reward system (Kornetsky and Esposito, 1979).

In rats with daily restricted access to heroin, reward thresholds were stable across days [Kenny et al. (2006), their Fig. 1C (http://www.jneurosci.org/cgi/content/ full/26/22/5894/F1)]. Thus, mere heroin exposure, even during several weeks, was not sufficient to alter brain reward. In contrast, in rats with prolonged access to heroin, reward thresholds gradually increased, probably because of a temporal summation of withdrawal effects [Kenny et al. (2006), their Fig. $1 D$ (http://www.jneurosci.org/cgi/ content/full/26/22/5894/F1)]. This elevation in reward thresholds paralleled the escalation of heroin intake [Kenny et al. (2006), their Fig. 1 A (http://www.jneurosci.org/cgi/content/full/26/22/5894/F1)]. These observations confirm previous findings in rats with escalating cocaine use (Ahmed et al., 2002) and suggest that a withdrawal-induced decrease in reward function drives compulsive heroin use.

To assess the impact of conditioned withdrawal on heroin consumption, withdrawal was repeatedly precipitated by naloxone, a competitive $\mu$-opioid receptor antagonist, and conditioned to a tone plus a light. As expected, in rats with re- stricted access to heroin, naloxone blocked heroin action on its receptors, thereby inducing a compensatory increase in heroin intake. In contrast, in heroindependent rats, naloxone not only blocked heroin action but also further decreased brain reward, as measured by an acute elevation in self-stimulation threshold above the already altered baseline [Kenny et al. (2006), their Fig. 3C (http:// www.jneurosci.org/cgi/content/full/26/ 22/5894/F3)]. This decrease in reward was associated with a more pronounced increase in heroin consumption compared with nondependent rats [Kenny et al. (2006), their Fig. 2 (http://www.jneurosci.org/cgi/ content/full/26/22/5894/F3)]. After conditioning, exposure to the tone-plus-light stimuli alone evoked effects similar to naloxone in dependent animals: they decreased reward activity and increased heroin self-administration (Fig. 1). These stimuli remained neutral in controls. These results clearly show that the shift to heroin dependence is associated not only with a quantitative change in heroin consumption, but also with a qualitative change in the motivation underlying heroin use, now driven by the anticipation of withdrawal.

This study raises several questions for future research. First, the mechanisms underlying the motivational effects of conditioned withdrawal are not entirely clear. According to the authors, withdrawalpaired stimuli acquired motivational significance because dependent animals 


\section{Non-dependent subjects}

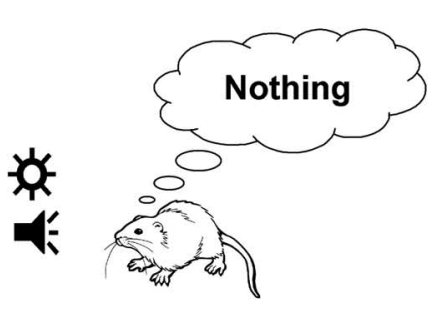

Reward activity

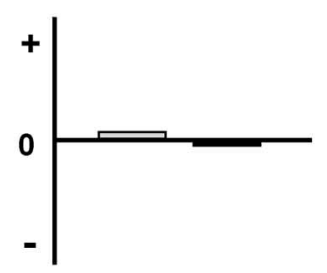

0

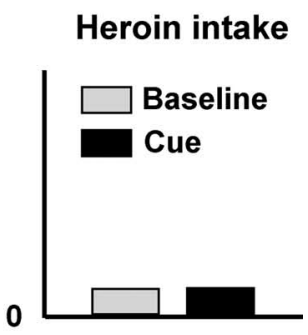

Heroin-dependent subjects

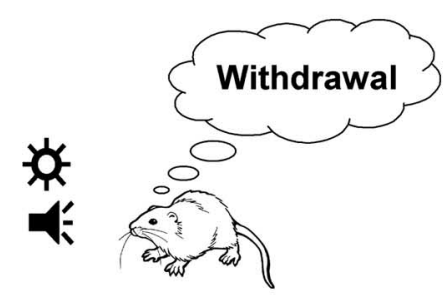

Reward activity

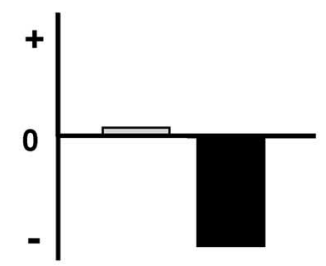

termine whether the authors' conclusions apply to naturally occurring drug withdrawal. Finally, it is important to recall that drug-paired stimuli (e.g., paraphernalia in human addicts) can also induce conditioned withdrawal responses in human addicts (Wikler, 1973). It would be of great interest to determine whether these stimuli alone can decrease reward function in drugdependent individuals, as do withdrawalpaired stimuli. This issue is critical, because drug-associated stimuli are probably more prevalent than withdrawal-paired cues in human addiction.

In summary, Kenny et al. (2006) provide evidence for a profound change in the motivation underlying heroin use that may be relevant to the transition to addiction in humans. The results predict that in controlled heroin users, heroin consumption would be essentially motivated by memories of the positive rewarding effects of the drug. In dependent users, however, the motivation to use heroin would be strengthened by additional memories of the negative affective consequences of withdrawal. It remains to be established whether these memories are sufficiently persistent to explain the long-lasting vulnerability to relapse in apparently recovered addicts.

\section{References}

Ahmed SH, Kenny PJ, Koob GF, Markou A (2002) Neurobiological evidence for hedonic allostasis associated with escalating cocaine use. Nat Neurosci 5:625-626.

Kenny PJ, Chen SA, Kitamura O, Markou A, Koob GF (2006) Conditioned withdrawal drives heroin consumption and decreases reward sensitivity. J Neurosci 26:5894-5900.

Kornetsky C, Esposito RU (1979) Euphorigenic drugs: effects on the reward pathways of the brain. Fed Proc 38:2473-2476.

Robinson TE, Berridge KC (2003) Addiction. Annu Rev Psychol 54:25-53.

Wikler A (1973) Dynamics of drug dependence. Implications of a conditioning theory for research and treatment. Arch Gen Psychiatry 28: 611-616. 